\title{
The Katateeb Al-Bidoon Initiative: Repurposing the Past to Build a Transformative Future
}

\author{
Abdullah Mansoor ${ }^{1}$ \\ ${ }^{1}$ University of Illinois at Urbana-Champaign, USA \\ Correspondence: Abdullah Mansoor, University of Illinois at Urbana-Champaign, 2020 Education Center, Room \\ 351, 1310 S. Sixth St., Champaign IL 61820-6925, USA. E-mail: Abdullah.m.edu@gmail.com
}

Received: June 5, 2021

Accepted: July 10, $2021 \quad$ Online Published: July 29, 2021

doi:10.5539/jel.v10n5p30

URL: https://doi.org/10.5539/jel.v10n5p30

\begin{abstract}
The Katateeb al-Bidoon initiative was an after-school teach-in combined with a series of government protests against the sudden expulsion of stateless Bidoon children from any official Kuwait school. Considered illegal residents, the Bidoon status in Kuwait has deteriorated over the past generation, and their exclusion from Kuwait society is nearly complete. Regardless, many educational activists and teachers still continue to support Bidoon access to education, and the Katateeb al-Bidoon initiative is one example of their work. The name Katateeb refers to the archaic casual school system that was prevalent in Kuwait before the era of oil urbanization. Though its lifespan was one brief semester, from October 2014 to February 2015, a close examination of the initiative provides insight into how an improvised pedagogy based on an educational model from the past can develop beyond expectations and support a transformative future.
\end{abstract}

Keywords: Bidoon, Katateeb al-Bidoon, Kuwait, education history, crisis pedagogy, alternative models of education

\section{Introduction and Background}

The Katateeb al-Bidoon initiative was launched in October 2014 to raise awareness of the struggle for access to education experienced by the stateless Bidoon children of Kuwait. This brief initiative was an almost instinctive reaction to an unexpected wave of Bidoon expulsions at the primary school level, and was made up of a series of actions in tandem with a semester-long after-school teaching program conducted at the Jahra offices of the Kuwait Teachers Society. Led by Yusuf al-Bishiq, project coordinator Ahmed al-Khulafi, and volunteer teacher Khadeeja al-Shammari, they named the initiative Katateeb al-Bidoon in honor of the archaic religious school system that educated Kuwait's children in the past; their declared goal was to prepare the Bidoon children for a future in which they will be able to fully participate in Kuwaiti society. Teachers and activists who supported this action placed it in the context of the global effort to achieve universal education (Azouz, 2013), citing the UN Convention for the Rights of The Child, emphasizing the key articles 28 and 42 (United Nations, 1989), which is also the basis for the United Nations Millennial Development Goals of equal access to education for all children, regardless of status (United Nations, 2015). In the future aspired to by initiatives such as the Millennial Development Goals and the United Nations High Commission for Refugees Ending Statelessness Initiative (UNHCR, 2014), statelessness will no longer be an impediment to education. This essay will explore and analyze the Katateeb al-Bidoon initiative, contextualized within the Bidoon struggle to achieve basic rights, the history of education in Kuwait, and the current global effort to ensure universal education, while reflecting on the impact of consciously utilizing an educational tradition from the past in an attempt to positively transform the future.

The Bidoon are a stateless population living within the borders of Kuwait, many of whom can trace their families to Kuwaiti territory for generations. When the British protectorate was dismantled in 1961, and Kuwait was established as a modern nation-state, approximately $33 \%$ of the population were given Kuwaiti nationality on the basis of being "establishing fathers/founders" of the new country. Another third of the population were naturalized as nationals, and the rest were designated as without nationality, translated to "Bidoon Jinsiya" in Arabic. The history of the Bidoon in Kuwait has followed a complex trajectory, leading the population to fluctuate in size and composition over the past five decades. According to official data, there are approximately 110,000 stateless people in Kuwait (Ali, 2016). However, some estimates have placed their number as high as 
180,000 (Bilal, 2016). At first tolerated by the Kuwait nation and given access to many of the same benefits as citizens, their status has eroded over generations and currently they are neither recognized as citizens nor as legal residents. Instead, they maintain the status of illegal residents, and this status is transferred across generations.

Along with the loss of access to employment and the national health care system, the Bidoon have been effectively shut out of the Kuwait public schools since 1992. Years of pushback and political agitation in support of Bidoon rights resulted in the establishment of the Central Agency for Remedying Illegal Residents Status in 2010-2011 (Central Agency for Remedying Illegal Residents Status Public Relations and Media Department, 2013). Also known as the Central Agency for Illegal Residents (CAIR), this administrative branch of the Kuwaiti government oversees and manages all aspects of the Bidoon relationship to the state, including the distribution of benefits to those Bidoon who choose to accept support. These benefits ostensibly include proper legal documentation such as birth certificates for Bidoon children and tuition assistance for those who enroll in the separate system of Arabic private schools. In reality, the Central Agency has made it difficult for Bidoon children to obtain a legal birth certificate unless the parents are willing to officially accept the government's definition of their status, which may involve a declaration that they are from another country such as Iraq. Along with a general reluctance to interact with the Central Agency, which has a reputation for rough treatment of the Bidoon, parents are not willing to apply for the necessary documents for their newborns out of a concern that it may require them to sign away any claim they may have as Kuwaitis. Due to this situation, many Bidoon children have had to make do with a record of live birth —obtained from the hospital where the child was born - which would have no value but for its acceptance by the Arabic private schools as sufficient identification for enrollment.

The Katateeb al-Bidoon initiative encompassed a brief but intense period of time, beginning when schools opened for their 2014 fall semester and the government of Kuwait began enforcing a policy of requiring proper documentation to attend any official school in Kuwait, public or private. As a result, children who had been prepared by their parents to attend school were stopped on the first day and turned away (Alshammari, 2019). At least 600 children were immediately impacted, with thousands more added in the following months (Elgayar, 2014). In response to the sudden expulsion, concerned teachers and activists who make up the Jahra Branch of the Kuwait Teachers Society attempted to continue the children's education in a spirit of improvisation (Elgayar, 2014). The fact that this action took place in Jahra, a city near the northern border area of Kuwait and Iraq, is not an accident of geography. Many Bidoon are concentrated in this agricultural area, partly due to the availability of casual work and partly because Bidoon status is prevalent amongst the northern tribes that make up part of the traditional population of Kuwait. In Jahra, the Kuwaiti people have a different perspective towards the Bidoon - one of tolerance and compassion - compared to Kuwait City, the capital.

The project was named in a moment of conflict when initiative leader Yusuf al-Bishiq was presenting his concerns about the sudden expulsion of first-graders to the government. "The idea came spontaneously in a discussion with one of the officials, whom I told that if these children could not [attend school], we would open a katateeb, which is the Mullah system before education in Kuwait" (Al-Bahaweed, 2014, para. 6). In a matter of weeks after the spontaneous remark by al-Bishiq, the Katateeb al-Bidoon was functioning both as an after-school program and as an organized series of protests at the Ministry of Education. In the morning, during regular school hours, Bidoon parents and their children stood in the parking lot of the Ministry of Education holding signs protesting their expulsion. Many children were wearing their school uniforms; this visual, along with the fact that they were protesting their expulsion during school hours, created a powerful impact.

The most heart-wrenching aspect of the protests was that they took place at 10AM, with Bidoon children showing up in their school uniforms, carrying posters, at a time when they should have been sitting in their classrooms, not protesting being denied their universal right to education. Imagine the psychological trauma and confusion this is going to inflict (Alshammari, 2014, para. 7).

The protest attracted many prominent human rights activists, including writer and activist Hadeel Bu Qurais and former MP Musallam al-Barak, who at the time of this action was facing a two-year prison sentence for a 2012 speech criticizing Kuwait's president ("Former opposition MP surrenders...", 2018). In addition to joining the ongoing protests at the Ministry of Education, on October 22, 2014, Hadeel Bu Qurais staged a sit-in at the Plaza al-Erada holding a pencil to symbolize the importance of access to education (Azouz, 2013). Plaza al-Erada, which approximately translates to free-will or self-will, was often the location of protests during the Arab Spring-related actions of 2011-2013, similar to Tahrir Square in Egypt.

The final major action of 2014 occurred November 22, when volunteer teacher Khadeeja al-Shammari organized a high-profile protest at the 2014 Kuwait International Book Fair. This prestigious annual event is sponsored by 
the National Council for Culture, Arts and Letters, the official cultural branch of the Kuwait government, similar to the National Endowment for the Arts in the United States. Improving the literacy rate and increasing the availability of books are important goals for many Arabic nations, making the Kuwait International Book Fair extremely popular and well-attended by people involved in education and the arts from Kuwait and neighboring countries. For the 2014 event, Khadeeja al-Shammari designed yellow t-shirts with the following statement: "Did you know that there are children who are deprived of an education in Kuwait?" (Alshammari, 2019, p. 64). She then organized a group of protestors who agreed to wear them as they marched silently around the fair. Soon, others joined their silent march, and eventually they were asked to leave. The goal was both advocacy and awareness raising, as attendees were unaware that any child could be deprived of an education in a country as wealthy as Kuwait.

While the protests were being organized and implemented, the volunteers at the Katateeb al-Bidoon began to fully develop their improvised pedagogy, teaching Arabic, English, and Islamic studies ("Stateless children...", 2014, para. 9) and the students settled in to their two separate classes. Some wore uniforms, as if they were still attending the Arabic private schools. Some wore their regular street clothes, a fact that only served to emphasize the unofficial and unusual state of affairs that had led to this education practice. As the first impact of the movement waned, the school volunteers soldiered on, finding the students eager to learn and excited about attending school (Al Majlliss Media, 2014). Coordinator al-Khulaifi continually emphasized in his interviews with press that the initiative was never designed to be a long-term solution (Kholaif, 2015; Hajji, 2014; Al-Bahaweed, 2014) and as the semester ended, the program closed. Throughout, government officials insisted that there was nothing extraordinary about the documentation required for Bidoon children to attend Arabic private schools, and in the end many Bidoon parents either capitulated to the requirements if they could or stopped trying to enroll their children in school.

\section{The Katateeb School System's Role in Kuwait History}

A custom of private, religious schooling reaches back to the foundation of Islam and is part of the Islamic tradition honoring the acquisition of knowledge (Buabbas, et al., 2010). Thus, the traditions of the Katateeb model of education are more deeply rooted in the culture of Kuwait than the state-sponsored system that developed in the 20th century. The term "al-katateeb" is plural for "al-kuttab", which is the word for "writer" (Al-Thowaini, 2015). In the Katateeb system, children were not required to attend and teachers were not mostly unpaid, with the exception of gifts received from parents if the child reached some desired milestone (Al-Thowaini, 2015). The education was offered to students who were of young primary school age, and gave them the opportunity to learn to read and write, with the intention that they would use those skills to read and study the Qu'ran. The Katateeb school, therefore, can be understood as an archaic grammar school, similar in form albeit with slightly different names across the Islamic world, devoted to developing numeracy and literacy for a mainly religious purpose. Today's education scholars refer to them as "primitive schools" (Al-Jasem, 1992; Buabbas et al., 2010), in reference to the fact that they had no dedicated building, no professional teachers, no set curriculum, and an extremely limited supply of educational materials. In the history of education, this is a commonly occurring system across cultures; for example, the private Dame schools and religious schools of medieval England and colonial America were similarly structured. Young students learned to read and write at a teacher's house, mainly for religious purposes, and the girls were additionally taught to sew or embroider (Higginson, 1974). At the Dame school, the Katateeb finds one parallel in history; throughout Western Europe there are many more (Grendler, 1990).

In Kuwait, a robust Katateeb educational system emerged in the late 1870s with the establishment of the first schools for males; in 1916 education was expanded to include girls and in 1926 the first school specifically for girls opened (Buabbas et al., 2010). In spite of the primitive nature, the lack of organizational structure or set curriculum, and limited topics of instruction, the consensus is that these schools had a positive and powerful impact on reducing illiteracy (Al-Abdulghafoor, 1983; Al-Jasem, 1992; Buabbas et al., 2010). Their small successes, however, would be overshadowed by the development of a central government-based education system that began to slowly develop under Kuwait's years as a British protectorate and then exploded after statehood. 


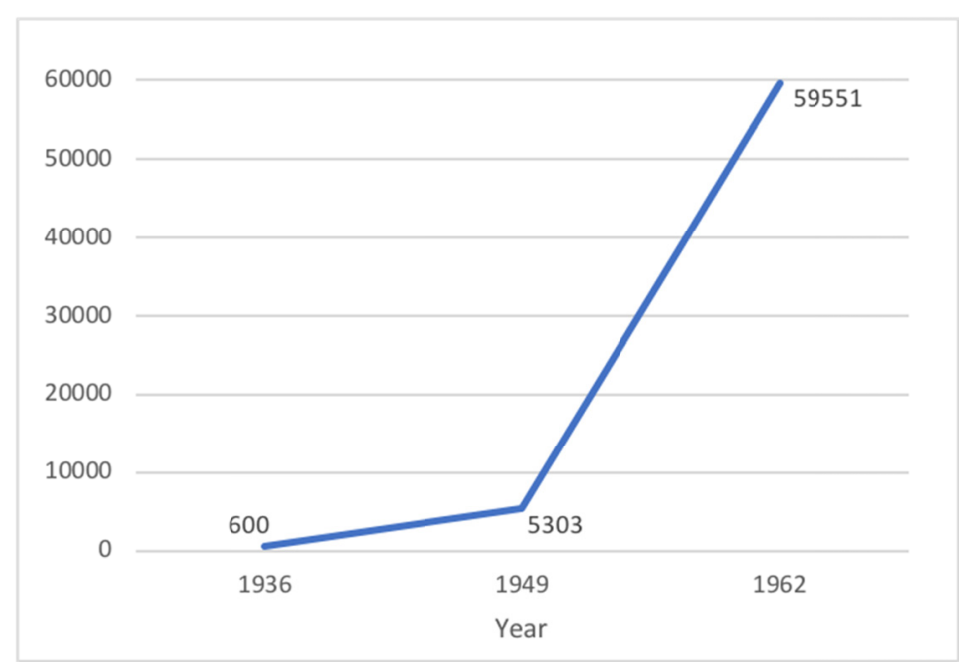

Figure 1. Number of students enrolled in Kuwait government schools, 1936-1962

Note. Adapted from "Hidden Parts in the History of the School Library in Kuwait", by H. Buabbas, B. Medjdoub, and Y. Rezgui, 2010, Library Review, 59(6), p. 406.

Thus began an era of massive governmental investment focused on technological innovation, modernization, and infrastructure development. which created the basis of the Kuwait public school system that exists today, presumably leaving the Katateeb system to the back pages of history.

\section{The Evolution of the Katateeb al-Bidoon}

From its dramatic beginning as a protest action that drew the attention of social media to the quiet close of its after school program months later, the Katateeb al-Bidoon initiative changed and developed over its one-semester lifespan, and the meaning of the name evolved into more than the original intent. When the leaders of the initiative chose this archaic name for their school, they used it as a sardonic critique of the government neglect that necessitated a reversion to a "primitive" style of schooling. The wit behind the attack relies on an understanding of Kuwait as a country that prides itself on its status as a wealthy and developed nation, moving forward with more and greater social improvements. By using the name of Katateeb al-Bidoon, the political message to the government was that their oppression of the Bidoon had the effect of taking Kuwait backwards into a less developed era of history. In the technologically-advanced, future-oriented nation of Kuwait, the Bidoon children were experiencing a neglectful and unhelpful system that recalled inefficiencies of governance from before statehood when schools were mostly supported by private individuals (Al-Jasem, 1992). Then as now, the Katateeb would be necessary to fill in the gaps left by a government unconcerned with the welfare of all its people. For a nation that prides itself on its technological advancement and a rich array of educational opportunities, the name Katateeb al-Bidoon can be interpreted as a criticism, and a suggestion that this high-tech society is not evenly distributed. As initiative leader Yusuf al-Bashiq stated in an interview with Al Talea, "It is inconceivable, after all the technological development in this country, we are back to opening Katateeb, but this is what happened" (Al-Bahaweed, 2015, para. 5). The sense was that the government of Kuwait should feel embarrassed that a school such as an old-fashioned Katateeb still needs to exist at all.

As the initiative progressed, the name began to assume layers of meaning beyond the ironic intent of its author and the Katateeb al-Bidoon took on a life of its own. Many Kuwaitis have positive associations with the Katateeb system, which remains a treasured part of the cultural tradition and legacy of Kuwait. It is undeniable that Kuwaitis are proud of the current educational system with its advances in technology, well-developed infrastructure, and great success at reducing illiteracy, giving fuel to the accusation inherent in the name Katateeb. However, many Kuwaitis also feel strong affection and nostalgia for the era just previous to the discovery of oil, and this name Katateeb al-Bidoon may have inspired greater warmth in the social media response, with members, for example, posting a picture from a true ancient Katateeb on social media in response to the story covering the Bidoon al-Katateeb (Azouz, 2014). The positive connotations of the term Katateeb also have something to do with the fact that the last generation of the Katateeb system are the current elders of Kuwait. It is the education system of Kuwait's grandfathers and grandmothers, the last generation to remember a Kuwait before oil-fueled urbanization. This respect and affection is embodied in the popularity of a meteorologist in Kuwait, a celebrity figure who has been on television for generations. He was the teacher of the 
current president of Kuwait at a Katateeb and tells stories on television about how he punished the president when he misbehaved in school. From these relationships that exist within many Kuwaiti families and in pop culture, it can be understood how the name Katateeb al-Bidoon invoked a beloved cultural symbol.

While the era immediately before the advent of the petroleum-based economy has a powerful nostalgic effect on all Kuwaitis, its appeal is even greater for the Bidoon. Due to the unique situation of the Bidoon in Kuwait, the reference to an idealized past inherent in the name Katateeb al-Bidoon could also be interpreted as a gesture meant to recall a time when there were no Bidoon, only Kuwaitis. Even when they were denied citizenship and took on the status of Bidoon, they were treated as more or less social equals for a generation and were permitted to attend public schools (Beaugrand, 2016). Now, rejected as stateless and shut out from society, the Bidoon are denied both their present and their past as Kuwaitis. Therefore, with the name Katateeb al-Bidoon, the leaders of the initiative were referencing a time before statehood when education did not depend on citizenship or legal status and it was not necessary to have official documentation to identify and be accepted as Kuwaiti.

As the initiative ended, a final meaning emerged from the name Katateeb al-Bidoon: a reference to a practical system which has been demonstrated to work when nothing else is available. Like the traditional Katateeb system, the Katateeb al-Bidoon had modest goals. In an interview with Kuwait Times at the beginning of the initiative, coordinator al-Khulaifi stated, "We are not a school, we are only a group of activists and volunteers who don't want these children to be deprived of their right of education, so we are doing what we can" (Hajji, 2014, para. 8). He elaborated on this point in another interview: "We can't grant accredited certificates; we offer an improvised form of education" (Elgayar, 2014, para. 16). A few weeks later, he reiterated, "We are not a regular school" (Al-Bahaweed, 2014). Whether or not it was a regular school, however the children kept coming, "in uniform, lunchboxes in hand, eager to learn anywhere and at any time" (Alshammari, 2014, para. 6). The volunteer teachers continued teaching. Week after week, the school continued to operate at capacity - an important metric of success for any school, small or large. In his final interview in February 2015 before the close of the program, al-Khulaifi stated once again, "This initiative cannot be a solution or an alternative, especially when at least 2000 Bidoon students across all academic stages, have been warned of expulsion if they provide no birth certificates" (Kholaifi, 2015, para. 10). The organizers were painfully aware of the small number of children they were able to educate- 50 - versus the thousands that were either expelled or threatened with expulsion (Al-Turki, 2014; Kholaif, 2015) and thus were careful to downplay the effectiveness of the Katateeb al-Bidoon as a school on par with the public schools or the Arabic private schools. One of the primary elements of a functioning school, however, is a population of students eager to learn, and when judging by attendance, the Katateeb al-Bidoon was functioning as an educational initiative. From the start, the volunteer teachers noticed that students were enthusiastic to learn and that some students were even quite gifted. For example, volunteer teacher Badria al-Turkil stated the following:

I was surprised that a large number of the students were so very intelligent. I didn't even need to put a huge effort into educating them, because they already grasped everything right away. It's a pity that these good, smart kids are not enrolled in the compulsory educational system. They lose their chance and their right to access education the same as other kids their age (Al Majlliss Media, 2014, 02, 25)

The focus on teaching and learning increased as the more high-profile protests ceased and the Katateeb al-Bidoon volunteers continued to teach their small cohort of first graders. From its beginning a symbolic and ironic gesture, the Katateeb al-Bidoon initiative underwent a metamorphosis into a functioning program, providing a brief educational opportunity to those handful of Bidoon children they were able to serve.

\section{Repurposing the Past}

The Katateeb al-Bidoon was designed to smooth the hard edges from a serious educational disruption for some Bidoon children, during an attempt to pressure the government to relent and allow the children to attend school with their record of live birth. As al-Khulaifi continually emphasized, it was not intended to replace school. Uniforms were not mandatory. The national morning rituals were not followed. The school did not take place during regular hours, and the volunteers taught all subjects, unlike the teacher-per-course structure of the official school system. Further, the Katateeb al-Bidoon still functioned to separate the Bidoon children from the rest of the children of Kuwait (Alshammari, 2014). The children's lives were turned upside down. They asked questions like, "Why aren't we in school? Why don't we sing the national anthem? Why are we missing our books? Where is our school uniform? Why is it the same teacher?" (Al Majliss Media, 2017, 01, 25). In the heartwarming images of young children writing diligently at their books or eagerly reciting a lesson, it is important for the viewer to remember that these children were undergoing great trauma and upheaval, with the Katateeb al-Bidoon functioning as an emergency tactic, an act of improvisation which the leaders and volunteers were making up as 
they went along.

If the Katateeb al-Bidoon cannot be called a school, neither can it be called a Katateeb by a strict historical definition. The setting of the Katateeb al-Bidoon remains squarely in in the post-oil urbanization present, and the time in which the original Katateeb flourished is long vanished. Of course, the initiative bore similarities to the original Katateeb system, which drove much of the energy behind its name. There was no official enrollment; volunteer teachers, many uncredentialed, taught a multiplicity of subjects; educational supplies were limited; and students were not compelled to attend. However, the Katateeb al-Bidoon was not a re-enactment of history. The classroom practice, for example, of the original Katateeb was based on strict memorization, and teachers used corporal punishment as a matter of course (Buabbas et al., 2010). In contrast, the volunteer teachers of the Katateeb al-Bidoon were working under the sponsoring entity of the Kuwait Teachers Society, whose stated goal is to partner with their communities to help them achieve educational goals (Kuwait Teachers Society, n.d.). The current pedagogy is a far cry from the common teaching and learning practices of the Katateeb era and have certainly not been resurrected in the Katateeb al-Bidoon, regardless of the name. The curriculum also differed from the historical Katateeb system. At the Katateeb al-Bidoon, the subjects taught were Arabic, English, and Islamic Education ("Stateless children...", 2014, para. 9). English was never taught in the traditional Katateeb. Further, as Yusuf al-Bashiq noted, the organizers were volunteer activists (Hajji, 2014), with a perspective driven by the global effort for universal education; they were not people holding religious office or affiliated with a mosque, which gave the Katateeb al-Bidoon a different character from its historical model. It is evident that evoking a name such as Katateeb does not mean a strict imitation of every practice and the Katateeb al-Bidoon is very much a product of innovations in $21^{\text {st }}$ century pedagogy, along with the theories of transformational education that inspired the initiative in the first place.

Neither contemporary school, nor historical relic, the Katateeb al-Bidoon was an improvised, creative effort that took on its own unique identity, based partly on the positive energy of the teachers and partly on the eager uptake of the Bidoon children, who were managing a crisis by holding fast to any stability and educational opportunity that was offered. By choosing to educate, support, and advocate for the Bidoon, the teachers and activists who participated in this initiative were making a strong statement, not just about a part-rejected and part-idealized past, but about their belief in a transformed future in which Bidoon would be accepted into Kuwait society. Their stated goal was a future of security and stability for all Kuwait, not just Bidoon. As one protest poster stated, "Learning deprivation = uncertain future" while another protest poster stated, "Ignore me today, you will have to listen tomorrow" ("Stateless children...", 2014). In an interview, one volunteer teacher stated, "I want these children to have a better future. I know they can make one for themselves with a better education. I don't want them to grow up to be fruit sellers on the side of the street just because they don't have the right papers and documents" (Hajji, 2014, para. 9). In the same interview, al-Khulaifi noted, "We want these kids to enjoy the basic rights of education, the basic dreams of childhood" (Hajji, 2014, para. 6). The Bidoon children were impacted by the positive vision of the initiative leaders, and thus had the emotional space and stability to visualize a bright future for themselves. When a little Bidoon girl attending the Katateeb al-Bidoon spoke of her dream of being a teacher (Elgayar, 2014), her words demonstrated the powerful impact of the Katateeb al-Bidoon on the imagination of the child. The Katateeb al-Bidoon - that brief island in time-existed long enough to engender and share a positive vision with the next generation, while giving them a chance to begin developing the tools they need to build that future.

In a moment of crisis, the teachers and activists of the Jahra branch of the Kuwait Teacher's Society reached out to the traditions of the past to create a bridge to a better future: the Katateeb al-Bidoon. This short-lived initiative - conceived as a tactic in the ongoing struggle between the Central Agency and the human rights actors that protect the rights of the Bidoon in Kuwait — stayed viable long enough to experience a brief moment as a functioning educational program. The Bidoon children continued to attend and were eager to learn throughout the initiative. Activists and theorists of transformational education can study this example and apply it to strategies for crisis education in the future. When a group of people are shut out from the official education system, for various reasons, the Katateeb al-Bidoon initiative demonstrates that the casual pedagogical models of the past can at least reduce literacy and thus improve outcomes for those affected. The Katateeb al-Bidoon initiative was able to continue the education of a cohort of 50 children for a semester with two offices repurposed into classrooms, ten volunteers, and a few coordinators. For Bidoon education specifically, whether or not it is it feasible to utilize this pedagogical model in the future depends on the will of the Kuwaiti people, Bidoon and citizen, to take educational matters into their own hands, as they did in the pre-oil urbanization era. Meanwhile, the Katateeb al-Bidoon initiative leaves as a legacy a tentative blueprint for a grassroots model of education that could at least reduce illiteracy among the Bidoon, empowering them in their struggle to achieve the dream of a 
safety and stability in the only home they've ever known.

\section{References}

Al Majlliss Media. (2014). Bidoon learn in Kateebs after being deprived of schools [Video]. Youtube. Retrieved from https://www.youtube.com/watch?v=Q-XWa9Qt2u8

Al-Abdulghafoor, F. (1983). The Development of Education in Kuwait 1912-1972. Al-Falah Press. Retrieved from https://www.noor-book.com/en/book/review/585500

Al-Bahaweed, S. (2014). The Bidoon writers project: A civilized protest against the denial of education for children. Al Taleea. Retrieved from https://altaleea.com/?p=9654

Al-Jasem, N. (1992). Education in Kuwait 1939-1943 in light of Adrian Valence's two reports. Journal of the Gulf and Arabian Peninsula Studies, 17(66), 28-33. Retrieved from http://pubcouncil.kuniv.edu.kw/jgaps/home.aspx?id=8\&Root=yes\&authid=1303\#

Al-Thowaini, M. A. (2015). Can I see me? A study of pictorial representations in Saudi elementary textbooks and teacher and curriculum developers' perceptions of multiculturalism. Doctoral dissertation, University of Pennsylvania. ETDA - Penn State. Retrieved from https://etda.libraries.psu.edu/files/final_submissions/10637

Al-Turki, A. (2014). Bidoon writers: A future that holds fast to God and education. Al Rai Media. Retrieved from https://www.alraimedia.com/Home/Details?id=1ccf465c-fle5-4706-a605-59b9cc9273c6

Ali, E. (2016). Bidoon in Kuwait: When looking for an identity within your own country. Non-Post. Retrieved from https://www.noonpost.com/content/12582

Alshammari, A. (2014). Kuwait sentences Bidoon children to illiteracy. ViewsWeek. Retrieved from https://viewsweek.com/kuwait-sentences-bidoon-children-illiteracy/

Alshammari, A. (2019). Sociopolitical narratives and contestations in Kuwait's creative sector post-2012. (Publication No. AAT 22621242). Master's thesis, Georgetown University. ProQuest Dissertations \& Theses Global. Retrieved from https://repository.library.georgetown.edu/bitstream/handle/10822/1056000/Alshammari_georgetown_0076 M_14389.pdf?sequence $=1$ \&isAllowed $=y$

Azouz, B. (2013). The civil rights of the Bidoon and the continued suffering [Online forum post]. National Kuwait. Retrieved

from https://www.nationalkuwait.com/forum/index.php?threads/250665/page-8\#post-3441390

Beaugrand, C. (2018). Stateless in the Gulf. I.B. Tauris. https://doi.org/10.5040/9781350988279

Bilal, L. (2016). Claims to naturalize stateless with documents, and armed forces members. Alanba'a. Retrieved from http://www.alanba.com.kw/anbapdf/newspaper/2007/06-jun/21/fp082162007.pdf

Buabbas, H., Medjdoub, B., \& Rezgui, Y. (2010). Hidden parts in the history of the school library in Kuwait. Library Review, 59(6), 401-413. https://doi.org/10.1108/00242531011053922

Central Agency for Remedying Illegal Residents Status Public Relations and Media Department. (2013). Illegal residents facts and figures. Kuwait: Central Agency for Remedying Illegal Residents Status Public Relations and Media Department.

Elgayar, A. (2014,). Kuwait's stateless residents struggle for education. Al-Fanar Media. Retrieved from https://www.al-fanarmedia.org/2014/11/kuwaits-stateless-residents-struggle-education/

Eltony, N. M. (2007). The economic development experience of Kuwait: Some useful lessons. Journal of Economic and Administrative Sciences, 23(1), 77-102. https://doi.org/10.1108/10264116200700003

Former opposition MP surrenders to Kuwaiti authorities. (2018). The National. Retrieved from https://www.thenational.ae/world/mena/former-opposition-mp-surrenders-to-kuwaiti-authorities-1.697304

Grendler, P. F. (1990). Schooling in Western Europe. Renaissance Quarterly, 43(4), 775-787. https://doi.org/10.2307/2862790

Hajji, H. M. (2014). 600 Bidoon children denied admission to local schools. Kuwait Times. Retrieved from https://news.kuwaittimes.net/pdf/2014/oct/15/p01.pdf

Higgenson, J. H. (1974). Dame schools. British Journal of Educational Studies, 22(2), 166-181. https://doi.org/10.1080/00071005.1974.9973404 
Kholaif, D. (2015). Kuwait makeshift school takes in shunned stateless students. Middle East Eye. Retrieved from https://www.middleeasteye.net/features/kuwait-makeshift-school-takes-shunned-stateless-students

Kohn, S. (2011). Stateless in Kuwait: Who are the Bidoon? Open Society Foundations. Retrieved from https://www.opensocietyfoundations.org/voices/stateless-kuwait-who-are-Bidoon

Kuwait Teachers Society (n.d.). Mission and vision. Retrieved from http://kts.org.kw/ar/about-us/mission-and-vision/

Stateless children deprived of education in Kuwait. (2014, November 9). France 24: The Observers. Retrieved from https://observers.france24.com/en/20141119-stateless-children-education-kuwait-bidoon

United Nations. (1989). Convention on the rights of the child. Treaty Series, 1577, 3. Retrieved from https://www.ohchr.org/en/professionalinterest/pages/crc.aspx

United Nations. (2015). The millennium development goals report. Millennium Development Goals and Beyond 2015. Retrieved from https://www.un.org/millenniumgoals/2015_MDG_Report/pdf/MDG\%202015\%20rev\%20(July\%201).pdf

United Nations High Commission for Refugees (UNHCR). (2014). Ending statelessness within 10 years. Retrieved from https://www.unhcr.org/cgi-bin/texis/vtx/home/opendocPDFViewer.html?docid=546217229\&query=Special \%20Report:\%20Ending\%20Statelessness\%20Within\%2010\%20Years

\section{Copyrights}

Copyright for this article is retained by the author, with first publication rights granted to the journal.

This is an open-access article distributed under the terms and conditions of the Creative Commons Attribution license (http://creativecommons.org/licenses/by/4.0/). 